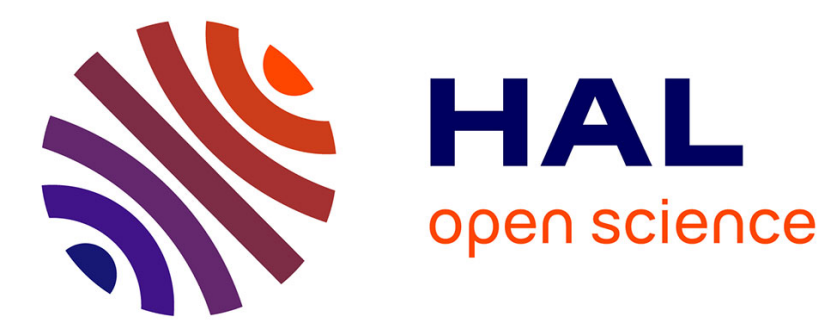

\title{
Reprogramming and Stemness
}

Lucie Laplane

\section{To cite this version:}

Lucie Laplane. Reprogramming and Stemness. Perspectives in Biology and Medicine, 2015, 58 (2), pp.229-246. 10.1353/pbm.2015.0022 . halshs-01279731

\section{HAL Id: halshs-01279731 https://shs.hal.science/halshs-01279731}

Submitted on 12 Sep 2018

HAL is a multi-disciplinary open access archive for the deposit and dissemination of scientific research documents, whether they are published or not. The documents may come from teaching and research institutions in France or abroad, or from public or private research centers.
L'archive ouverte pluridisciplinaire HAL, est destinée au dépôt et à la diffusion de documents scientifiques de niveau recherche, publiés ou non, émanant des établissements d'enseignement et de recherche français ou étrangers, des laboratoires publics ou privés. 


\title{
Reprogramming and Stemness
}

Lucie Laplane $e^{1,2}$

1 - INSERM U1170, Gustave Roussy, Université Paris-Sud, Villejuif, France

2 - Institut d'Histoire et de Philosophie des Sciences et des Techniques, Université Paris I-Panthéon Sorbonne, Paris France

\section{Correspondence:}

Lucie Laplane

114 Rue Edouard Vaillant

94800 Villejuif, France.

E-mail: lucie.laplane@gustaveroussy.fr.

\begin{abstract}
Reprogramming technologies show that cellular identity can be reprogrammed, challenging the classical conception of cell differentiation as an irreversible process. If non-stem cells can be reprogrammed into stem cells, then what is it to be a stem cell, and what kind of property is stemness? This article addresses this question both philosophically and biologically, states the different possibilities, and illustrates their potential consequences for science with the example of anti-cancer therapies.
\end{abstract}

\section{Acknowledgment}

The author is grateful to Allan Beke, Eric Solary, and Michel Vervoort, as well as to Adam Ferner, Kate MacCord, Francesca Merlin, Thomas Pradeu, and an anonymous reviewer for their comments on earlier versions of this text. She would also like to thank the organizers of the conference "From Gene to Genome as an Integrated System." The author's research is currently funded by the SOCRATE program at Gustave Roussy. 
The discovery "that mature differentiated cells can be reprogrammed to a pluripotent stem cell state" earned John Gurdon and Shinya Yamanaka the 2012 Nobel Prize in Physiology or Medicine (Nobel Foundation 2012). They discovered that development and differentiation do not cause irreversible change in the cell: mature somatic cells and their nuclei can reacquire a stem cell identity. This discovery has been described as a paradigm shift in our understanding of cellular differentiation (Burns and Blau 2014; Cox and Rizzino 2010; Vogel and Normile 2012). Yet the consequences of this discovery for stem cell biology have not been fully investigated.

In this article, stem cell identity will be questioned in the light of the history of reprogramming. What does it mean to be a stem cell? I will first review how reprogramming technologies have questioned the classical conception of cell differentiation and development. As reprogramming has shown that non-stem cells can become stem cells, and thus acquire stemness in vitro, it has raised philosophical questions about the nature of stemness as a property. Current knowledge in stem cell biology reveals that stemness can be considered as a categorical property, a dispositional property, a relational-extrinsic property, or a systemic property. In a given system (such as cell population, tissue, organ, or organism), the identity of the stem cells depends on two main criteria, namely whether non-stem cells of that system can acquire stemness, and whether the microenvironment plays a determinant role in the acquisition or maintenance of stemness. This issue is worth addressing because different possible identities can have different consequences for science, as I will illustrate with the example of some anti-cancer therapies whose efficiency depends on stemness identity.

\section{Reprogramming Challenges Differentiation}

To understand the paradigm shift created by the work of Gurdon and Yamanaka, among others, it is important to note that differentiation was historically conceived as a unidirectional and irreversible process. As Vogel and Normile (2012) put it: "Life is a one-way trip. Plants and animals start as embryos and progress through irreversible developmental stages to eventual death" (178). This view of differentiation applies both to the development, through which a single fertilized cell gives rise to a complex multicellular organism, and to the maintenance of the organism, which relies on the constant production of differentiated cells by small pools of specialized stem cells able to self-renew and to differentiate.

Several common definitions of development convey this idea of irreversibility, like the definitions of development as an irreversible increase of complexity over time or as an increasing restriction of fate (Arthur 1997; Johnson 2001; reviewed in Pradeu et al. n.d.). During development, the cells progressively differentiate and simultaneously lose potential for differentiation. In multicellular organisms such as mammals, only the fertilized eggs (zygotes) and the blastomeres that derive from the first divisions of the zygotes are totipotent. The cells then start to move toward different cell fates. At the blastocyst stage, the embryo (a round partly hollow ball) contains two populations of cells. The trophoblast cells (the outer layer of the blastocyst) will participate to the development of the placenta, while the inner cell mass will give rise to the fetus itself. Colonies of pluripotent stem cells called embryonic stem (ES) cells can be derived from the inner cell mass. Those stem cells can give rise to all the cell types of the organism, but they can no longer develop into a new organism because they lack the ability to give rise to the extra-embryonic tissues, such as the placenta, that are required for the development of the fetus.

The potential of differentiation further decreases with the formation of the three germ layers during gastrulation. Cells move toward differentiation into ectoderm, mesoderm, or endoderm, and can no longer give rise to cells of the two other layers. Eventually, development gives rise to an organism whose stem cells only produce the cells of the tissue to which they belong. They are called "multipotent" or "tissuespecific" stem cells. ${ }^{1}$ Therefore, cell differentiation occurring during development appears as an irreversible process, an idea that has persisted since the very beginning of cellular biology (see Maienschein 2014; Rather 1978).

Cellular differentiation in adult organisms also seems irreversible. The cells of the organisms are constantly being renewed. In most cases, a small subpopulation of undifferentiated stem cells ensures the production and renewal of the differentiated cells. In the hematopoietic system, which is often considered as a model for understanding

\footnotetext{
${ }^{1}$ Some tissue-specific stem cells are only unipotent-that is, they can give rise to only one cell type. Whether unipotent stem cells can really be considered as stem cells is subject to debates that I have discussed elsewhere (Laplane 2015).
} 
the homeostatic maintenance of the tissues (Bryder, Rossi, and Weissman 2006), a small population of multipotent stem cells gives rise to progenitors that progressively differentiate toward different lineages (Figure 1). When assessed in vitro, cellular differentiation appears rigorously determined and irreversible. Once a hematopoietic progenitor moves into a lineage of differentiation, it no longer gives rise to cells of the other lineages (Till and McCulloch 1980). In vivo, stem cells can rescue the hematopoietic system of irradiated mice, thanks to their ability to long-term self-renew and to differentiate. However, multipotent progenitors can only rescue the hematopoiesis for a restricted period of time, due to a limited self-renewal potential. And more differentiated cells do not graft. Taken together, these in vitro and in vivo assays reinforce the idea that cellular differentiation is an irreversible process.

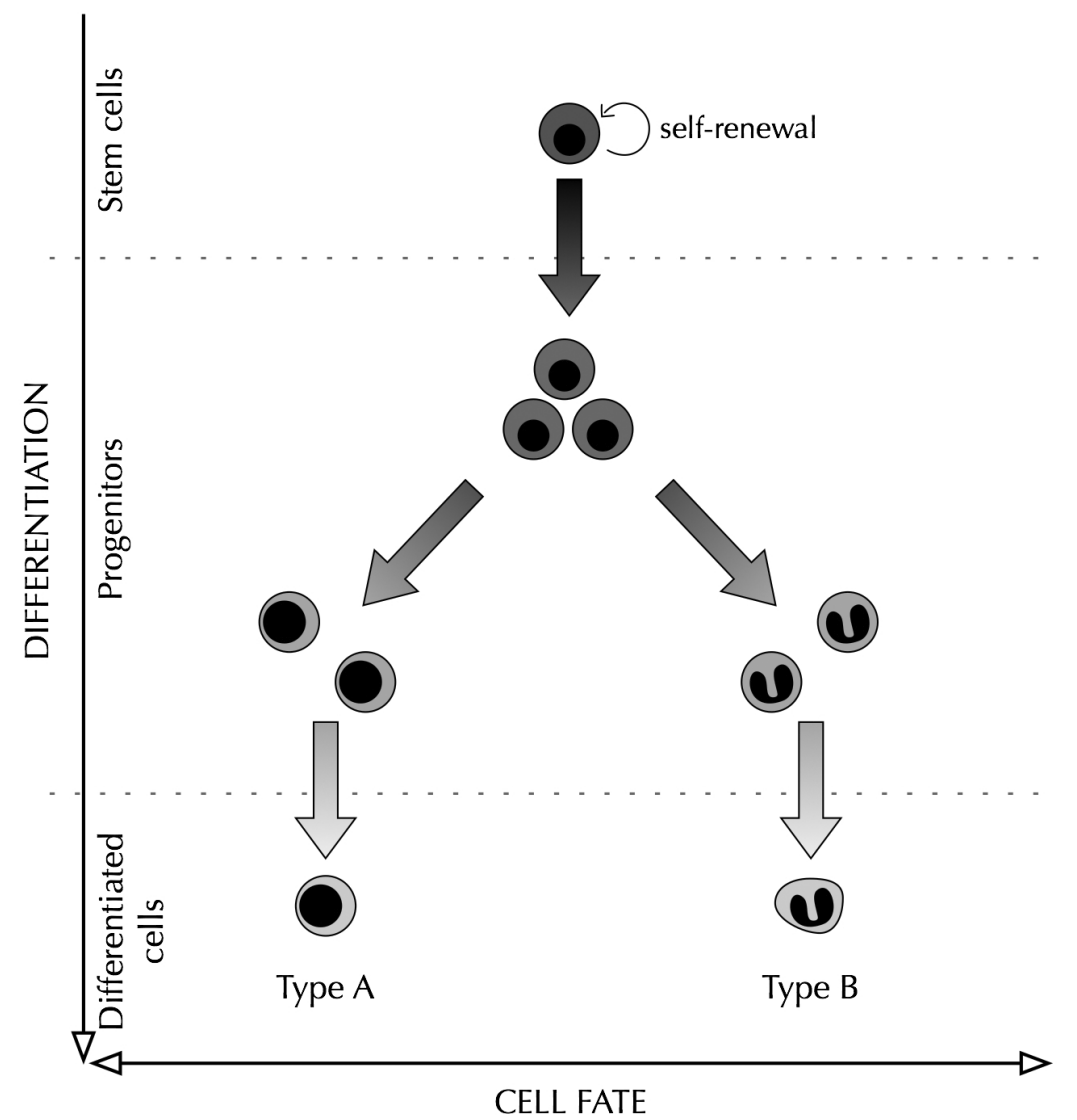

Figure 1 - Schematic representation of stem cell differentiation as an irreversible process.

\section{Nuclear Transfer}

The 2012 Nobel Prize in Physiology or Medicine rewarded the discovery that differentiated cells can in fact be reprogrammed to a stem cell state, questioning the irreversibility of differentiation. Interestingly, the history of reprogramming first confirmed the idea that differentiation during development is an irreversible process. Investigating the respective role of the nucleus and of the cytoplasm in differentiation and determination of the cell identity, Hans Spemann suggested in 1938 the idea of introducing nuclei of cells at different stage of development into enucleated oocytes, without knowing how to do it (Maienschein 2014). The first successful attempt at such an experiment came from Robert Briggs and Thomas King in the early 1950s (Briggs and King 1952). They transplanted the nuclei of cells of the leopard frogs Rana pipiens in early developmental stages into enucleated eggs, which gave rise to normally differentiating embryos. When they tried with the nuclei of cells of later developmental stages-endoderm cells of late gastrulae-they obtained normal cleavage and blastula formation, but development was then arrested and never gave rise to larvae. They concluded that "nuclei undergo certain changes during differentiation" that were associated with an irreversible restriction in their potential for differentiation (King and Briggs 1955, 324).

In contrast with these results, in 1962, John Gurdon published the result of the first successful nuclear transfers from mature cells. Using another frog, the South African Xenopus laevis, Gurdon transferred the nuclei of 
intestinal epithelium cells into enucleated egg cells and obtained normal development of tadpoles. He was then able to conclude that at least in these successful cases, the "intestine nuclei have the genetic information required to form normal feeding tadpoles" (635). With these reprogramming experiments, Gurdon proved that differentiation of the nucleus is a reversible process: provided the right cytoplasmic environment, a nucleus of a differentiated frog cell could return to a totipotent state. But was that also true for mammals? For decades reprogramming was viewed as a "frog phenomenon" (Blau 2014). Then came the birth of the famous clone Dolly the sheep in 1996.

Ian Wilmut and colleagues (1997) performed the first successful nuclear transfer from adult mammal somatic cells. They used adult mammary gland cells of sheep as donor cells, and transplanted not only the nucleus but also the cytoplasm into an enucleated egg cell and obtained one birth out of 277 attempts: Dolly. They saw this result as a confirmation that cellular differentiation does not involve irreversible genetic modifications: "The fact that a lamb was derived from an adult cell confirms that differentiation of that cell did not involve the irreversible modification of genetic material required for development to term" (810). However, as the efficiency of the nuclear transfer was low, doubt remained as to whether the nucleus that was successfully transferred was from a differentiated mammary gland cell or from a stem cell residing in that tissue (Weissman 2000). In order to test this hypothesis, Konrad Hochedlinger and Rudolf Jaenisch (2002) performed a nuclear transfer from mature lymphocytes. While they differentiate, $B$ and $T$ lymphocytes undergo genomic rearrangements at some particular loci ( $B$ and $T$ cell receptors). These rearrangements represent stable genetic markers attesting to the differentiated state of the donor cell. The development of mice carrying such rearrangement confirms that mature cells can be reprogrammed. Hochedlinger and Jaenisch (2006) were able to conclude: "The cloning of mammals from differentiated donor cells has refuted the old dogma that development is an irreversible process. It has demonstrated that the oocyte can reprogram an adult nucleus into an embryonic state that can direct development of a new organism" (1061).

\section{Induced Pluripotent Stem Cells (iPSC)}

Nuclear transfers brought to light the ability of the nucleus to revert to a totipotent undifferentiated state. However, the question of whether the cell itself could revert from a differentiated state to an undifferentiated stem cell state remained open.

The fact that the nuclei of differentiated cells were able to return to a totipotent or pluripotent state following nuclear transplantation led Shinya Yamanaka's team to hypothesize that oocytes must contain intrinsic factors that can reprogram the cells. Furthermore, some factors able to switch cell identity had already been discovered, such as MyoD, which can convert mouse embryonic fibroblasts into myoblasts (Davis, Weintraub, and Lassar 1987). Yamanaka's team thus wanted to find which factors, during nuclear transfer, were able to reprogram the nuclei of the differentiated cells.

Yamanaka hypothesized that the genes involved in the maintenance of pluripotency in cultured ES cells might be able to reprogram differentiated cells. He used a database containing genes expressed in different cells, available online at the National Center for Biotechnology Information (NCBI), to identify a list of genes that would be specifically expressed in ES cells. His team studied many of these genes, and by 2004 they had identified a list of 24 candidate reprogramming factors. They first separately introduced each candidate gene in mouse fibroblasts, using viruses as vehicles, and were not able to reprogram the cells. But when transducing the fibroblasts with all the 24 factors together, they obtained colonies of cells with morphologies similar to that of mouse ES cells and expressing ES cell markers such as Oct3/4, Nanog, E-Ras, Cripto, Dax1, Zfp296, and Fgf4. Then, by withdrawal of individual factors, they were able to find that a combination of four factors-Oct3/4, Klf4, Sox2, and c-Mycwas sufficient to produce ES cell-like colonies. The cells were called "induced pluripotent stem cells" (iPSC), as they were able to differentiate into the three germ layers and could produce adult chimeras when injected into mouse blastocysts (Takahashi and Yamanaka 2006). A year later, in 2007, the team reported obtaining human iPSC (Takahashi et al. 2007).

As in the case of nuclear transfer, the iPSC technology is quite inefficient, around $0.05 \%$ in the initial report, which again led to a debate between two interpretations, referred to as the "elite" and "stochastic" models (Yamanaka 2009). According to the stochastic hypothesis, iPSCs are truly derived from differentiated cells, and the lack of efficiency could be partly explained by stochastic factors and partly overcome by changes in the experimental protocols. According to the elite hypothesis, only tissue-specific stem cells could be reprogrammed 
to pluripotency, which would explain the low efficiency of the technology (see, for example, Kuroda et al. 2010; Wakao, Kitada, and Dezawa 2013).

Several articles reported successful reprogramming of T cells and B cells, in accordance with the stochastic model (Brown et al. 2010; Choi et al. 2011; Hanna et al. 2008; Staerk et al. 2010). However, data show that tissue stem cells dedifferentiate to a pluripotent state much more easily than differentiated cells. For example, Hochedlinger's team has shown that hematopoietic stem cells and progenitors give rise to iPSCs up to 300 times more efficiently than terminally differentiated $B$ and $T$ cells do, suggesting a middle ground between the stochastic and the elite models (Eminli et al. 2009; Gracio, Cabral, and Tidor 2013; Stadtfeld and Hochedlinger 2010).

The production of pluripotent stem cells from differentiated cells shows that cellular differentiation is a reversible process, at least in vitro. The question then is whether such stemness acquisition happens in vivo. And this raises an important issue about the identity of stem cells: is stemness an extrinsic property that any cell can acquire?

\section{Regeneration: Is Stemness Intrinsic or Extrinsic?}

Stemness is usually conceived of as an intrinsic property. However, with nuclear transfer and iPSC, we face conflicting interpretations of stemness and cellular identity. On the one hand, reprogramming shows that the cell fate is not irreversibly determined and that differentiated cells can "acquire" stemness, suggesting that stemness would be an extrinsic property. On the other hand, in the case of nuclear transfer, the oocyte contains all the factors that are necessary for the reprogramming of the nuclei. Reprogramming by cell fusion, which involves fusing adult cells with ES cells, also indicates that ES cells contain these factors (Tada et al. 2001). These results led Yamanaka (2013) to hypothesize that "oocytes or ES cells contain intrinsic factors that can reprogram somatic cells into a pluripotent state" (13904). His iPSCs confirmed this hypothesis, since they were reprogrammed through the use of such factors. Thus, the acquisition of stemness depends in these cases on intrinsic factors that are specific to pluripotent/totipotent stem cells, suggesting that stemness would be an intrinsic property. However, these cases of reprogramming are highly artificial. They show that stemness acquisition is possible, but can it really happen in vivo? And if it can, would that mean that stemness is an extrinsic property?

The scientific literature contains a number of references to dedifferentiation and cellular plasticity in vivo, in particular in the context of regeneration-that is, reconstruction of lost body parts. In plant biology, the ability of differentiated cells to dedifferentiate to a stem state is widely accepted (see Grafi 2004; Lohmann 2008). In animals, cardiac regeneration and retina regeneration in zebrafish, as well as limb regeneration in salamanders, are thought to rely on a first step of dedifferentiation of some cells (Bernardos et al. 2007; Echeverri, Clarke, and Tanaka 2001; Jopling et al. 2010; Kikuchi et al. 2010; Nye et al. 2003; Ramachandran, Fausett, and Goldman 2010; Satoh, Bryant, and Gardiner 2008; Satoh et al. 2008; Wan, Ramachandran, and Goldman 2012). Interestingly, Juan Carlos Izpisua Belmonte's team compared regeneration and reprogramming and found that two transcription factors involved in iPSC reprogramming, Sox2 and Oct4, were also involved in dedifferentiation prior to regeneration in zebrafish (Christen et al. 2010; see also Zhu et al. 2012). In addition, accumulating data suggest that in mammalian epithelia the hierarchy of differentiation might be more plastic than previously thought, with non-stem cells being able to revert to a stem cell identity during tissue repair and regeneration, as well as in some epithelial cancers (Donati and Watt 2015; Tetteh, Farin, and Clevers 2015).

Taken together, these data suggest that at least some types of non-stem cells can also acquire stemness in vivo, in particular contexts like regeneration, repair, or cancer (Figure 2). These context-dependent acquisitions of stemness suggest that for these cell types stemness might depend not only on the feature of the cells, but also, and mainly, on something else. If true, then on what else exactly does stemness depend? 


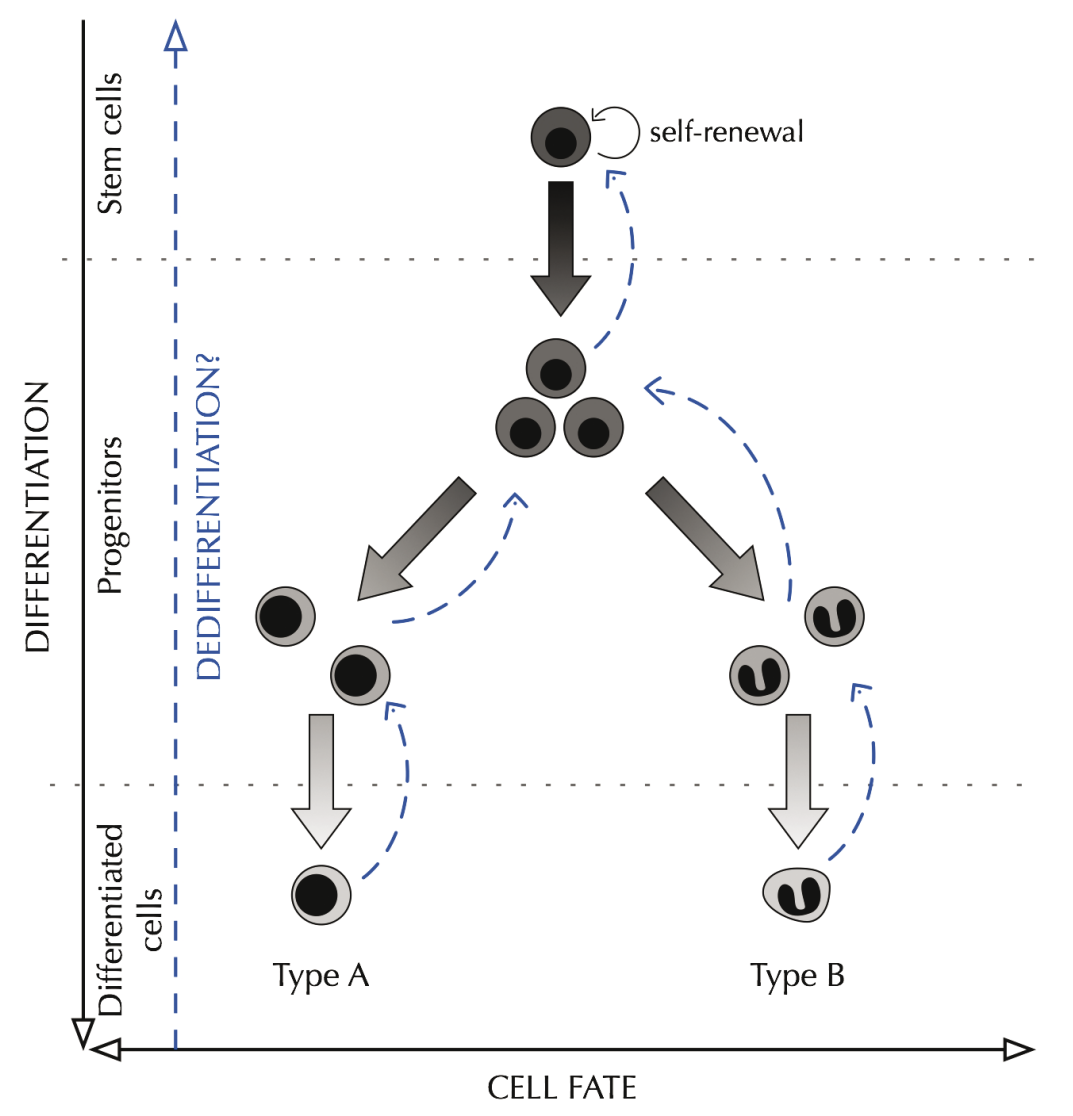

Figure 2 - In some contexts cells can dedifferentiate.

\section{The Niche Hypothesis: Is Stemness a Relational Property?}

How non-stem cells dedifferentiate to a stem cell state in regeneration, repair, or cancer contexts remains poorly understood. Data suggest that the microenvironment wherein the stem cells usually reside, called the "niche," could induce stemness in non-stem cells. The niche, more precisely, refers to a supportive cell to which the stem cell adheres and to the soluble factors co-localized in that intercellular microenvironment. For example, it has been shown that drosophila's germ cells can acquire stemness if they reenter the germ stem cell niche (Brawley and Matunis 2004; Cheng et al. 2008; Kai and Spradling 2004; Sheng, Brawley, and Matunis 2009). The same could be true for germ cells in mouse testes (Barroca et al. 2009). Stated philosophically, the niche offers a relational-extrinsic understanding of stemness identity: stemness is an extrinsic property that emerges on a specific relationship between the cell and the niche.

The concepts of relational property and extrinsic property are often used interchangeably (Weatherson and Marshall 2014). However, in the case of stem cells, this would be a mistake for two reasons. First, the niche might not always be involved in stemness acquisition. Second, the niche might play a determinant role in the expression rather than acquisition of stemness.

First, the niche might not always be necessary for stemness acquisition. For example, sorting breast cancer cells in several subpopulations, one containing stem cells and the others containing basal cells or luminal cells, Eric Lander's team observed that during in vitro culture each subpopulation returned to the initial equilibrium, suggesting that some basal cells and luminal cells acquired stemness in the absence of specific structured niches (Gupta et al. 2011). In this example, stemness appears to be another kind of extrinsic property, which can be referred to as a "systemic property," where it is maintained and controlled at the level of the system (here a cell population in a petri dish). A systemic property is a function of the system: it persists over time in a given system, and different entities within that system can acquire the property at different time points. In this case, understanding stemness requires taking the whole system into account, not just the stem cell (as would be the case if stemness was an intrinsic property) or just a specific relationship between a cell and a niche (as would be the case if stemness was a relational-extrinsic property). 
Second, the scientific literature on the stem cell niche contains two interpretations of the role of the niche with regard to stemness: strong and weak. In the first case, stemness is understood as both relational and extrinsic, whereas in the second case, it is considered as relational and intrinsic. According to the strong interpretation, the niche determines stemness-that is, it can induce stemness in non-stem cells. Ray Schofield (1978), who first framed the niche hypothesis in the late 1970s, suggested that when leaving the niche, stem cells inexorably differentiate, but that if a non-stem cell enters a vacant niche, it would regain the stem cell identity:

Stem cell properties do not reside in one specific cell type in the population but, when necessary, cells other than those normally playing the stem cell role, can have stem cell function imposed upon them by the appropriate microenvironment. . . . There are no cells which are intrinsically stem cells. (Schofield 1983, 375)

In contrast, according to the weak interpretation, the niche can only control stemness in cells that already are stem cells. That is, the niche provides signals that determine whether or not, for example, a given stem cell will divide or stay quiescent (Arai and Suda 2008; Clevers, Loh, and Nusse 2014). ${ }^{2}$ In this conception of the role of the niche-the most current one-stemness is a relational-intrinsic property. More precisely, it is a disposition: an intrinsic property (only stem cells have stemness) whose expression depends on extrinsic stimuli (here produced by the niche). Stemness as a disposition contrasts with the idea of intrinsic non-relational properties, that is, with the idea that stemness would be a categorical property: a property that would depend only on what stem cells are.

To sum up, two biological questions-can cells acquire stemness, and does the niche play a determinant role in stemness? - cluster into four distinct stem cell identities: stemness can be (1) a categorical property, (2) a dispositional property, (3) a relational-extrinsic property, or (4) a systemic property (see Table 1; for a more detailed analysis, see Laplane n.d.).

\section{Consequences of Stem Cell Identity for Anticancer Therapies}

Stemness identity has several consequences for stem cell biology and medicine. Here, I develop one example in oncology, where the efficacy of some therapies depends on the kind of property that stemness is. Stemness plays an important role in cancers. Since the 1990s, biologists have identified cancer cells with stemness properties, or "cancer stem cells" (CSCS), in many cancers (Kreso and Dick 2014). When CSCs and non-CSCs are separately sorted and transplanted into immunodeficient mice, only CSCs give rise to tumors, suggesting that they are responsible for the initiation and development of cancers (see, for example, the seminal transplantation studies of Bonnet and Dick 1997). CSCs are also suspected to be more resistant to therapies and could be responsible for relapses (Alison, Lim, and Nicholson 2011). These observations led to the idea that "in order to cure cancer, it is necessary and sufficient to kill CSCs" (Reya et al. 2001, 110), but the answer to the question of the stem cell identity might challenge this assertion.

The CSCs-targeting strategy relies on the implicit presupposition that stemness is an intrinsic property. If stemness is an extrinsic property, then non-CSCs can acquire stemness, as in the experiment conducted by Lander's team. In this case, eliminating the CSCs of a given cancer cannot guarantee a definitive recovery of the patient: at any time, non-CSCs could acquire stemness and either maintain the tumor or lead to a relapse. Since 2006, data suggesting that non-CSCs can indeed acquire stemness has started to accumulate, in particular for breast cancers, colorectal cancers, melanoma, and pediatric brain tumors (Chaffer et al. 2011, 2013; Gupta et al. 2011; Landsberg et al. 2012; Mani et al. 2008; Scheel et al. 2011; Thirant et al. 2011; Vermeulen et al. 2010).

\footnotetext{
${ }^{2}$ For example, in the hematopoietic system, Angiopoietin-1 and thrombopoietin, produced by mesenchymal and stromal cells constituting the hematopoietic stem cells niche, bind to Tie-2 and Mpl receptors, respectively. This activation of the receptors results in the activation of the expression of both $\beta$-catenin (a binding protein) and CDK repressors, which induce quiescence.
} 
If killing the CSCs is not sufficient to eliminate stemness from the cancer cell population-in other words, if stemness is an extrinsic property-then how can we achieve this goal? Targeting the extrinsic factors that determine stemness is a possibility. Stemness acquisition in vivo remains a poorly understood phenomenon.

\begin{tabular}{lll}
\hline & $\begin{array}{l}\text { Niche DOES NOT determine } \\
\text { stemness (non-relational) }\end{array}$ & $\begin{array}{l}\text { Niche DOES determine stemness } \\
\text { (relational) }\end{array}$ \\
\hline $\begin{array}{l}\text { Non-stem cells CAN acquire } \\
\text { stemness (extrinsic) }\end{array}$ & $\begin{array}{l}\text { SYSTEMIC } \\
\text { Extrinsic property controlled at } \\
\text { the system level }\end{array}$ & $\begin{array}{l}\text { RELATIONAL-EXTRINSIC } \\
\text { Extrinsic property determined by } \\
\text { niche-cell relationship }\end{array}$ \\
$\begin{array}{l}\text { Non-stem cells CANNOT acquire } \\
\text { stemness (intrinsic) }\end{array}$ & $\begin{array}{l}\text { CATEGORICAL } \\
\text { Intrinsic property depends only on } \\
\text { stem cell properties }\end{array}$ & $\begin{array}{l}\text { DISPOSITIONAL } \\
\text { Intrinsic property whose } \\
\text { expression depends on extrinsic } \\
\text { stimuli sent by the niche }\end{array}$ \\
\hline
\end{tabular}

Table 1 - What Kind of Property Is Stemness?

Several factors might be implicated, one of which is the stem cell niche. Whenever the niche is necessary for stemness expression, eliminating the niche or disrupting the relationship between the stem cells and the niche would equate to eliminating stemness. Such a niche-targeting strategy would be efficient both if stemness is a relational-extrinsic property and if it is a dispositional property. However, it would not guarantee a definitive cure if stemness is a systemic property, as other factors might induce stemness in absence of niche signaling.

How can we cure cancers if stemness is a systemic property? As multiple factors can be involved in stemness acquisition, a targeting strategy seems unpromising. System biologists represent cells' identities as positions in a mountain landscape made of hills and valleys (see, for example, Huang 2011). Hills represent unstable states, and valleys stable states. The stem cell begins at the top of the mountain, and its movement down towards the valley represents differentiation from highly unstable states to much more stable states. The more stable a cell is, the less it is susceptible to change and therefore to acquire stemness. Research in cloning and iPSC supports this view, as the reprogramming of undifferentiated cells is much more efficient than the reprogramming of differentiated cells (Eminli 2009). Thus, if stemness is a systemic property, differentiation therapies that aim to move the cell downhill could be efficient, with their efficiency directly correlating with the stability of the induced cell states. The less susceptible the cells are to acquiring stemness, the less the cancer may resist therapy and the less the patient would therefore be prone to relapse.

Thus, determining whether stemness is a categorical property, a dispositional property, a relational-extrinsic property, or a systemic property is important, at least in medical context. In cancers, the efficiency of therapeutic strategies directed against CSCs or their niches will predictably depend on the identity of stemness.

\section{From Theory to Practice}

There is often a huge gap between theory and practice, and the efficiency of therapies relative to stemness identity might be more flexible than it appears theoretically. First, there is a gap between a therapeutic strategy and the actual drugs. For example, in theory, CSC-targeting drugs should be able to cure cancer if stemness is a categorical or a dispositional property. However, we do not know exactly how to specifically target the CSCs. In addition, even if we did, some CSCs might be located in places where the drug is not delivered. Moreover, CSCs are subject to clonal evolution-that is, they can evolve into different subclones through accumulation of mutations and selection pressures (Greaves 2013). If CSCs are heterogeneous, then a CSC-targeting therapy might miss some of them.

Current differentiation therapies offer another example of the gap between theory and practice. In theory, they are supposed to deplete cancers from immature cells by forcing the differentiation of the immature cells, including CSCs. In practice, current effective differentiation therapies are rather targeted therapies that reverse differentiation blockades caused by genetic alterations. For example, in acute promyelocytic leukemia (APL), retinoic acid (RA) restores normal differentiation by degrading the PML/RAR $\alpha$ fusion protein that results from a translocation between chromosomes 15 and 17 and that causes an arrest of maturation in myeloid cell 
differentiation at the promyelocytic progenitor stage (Wang and Chen 2008). RA generally results only in transient disease clearance, and it becomes curative when combined with arsenic trioxide (As203) that also induces PML/RAR $\alpha$ degradation. It was thought that the therapeutic benefit of RA and arsenic resulted from the induction of terminal cell differentiation. However, the failure of such differentiation to eradicate the disease in APL expressing the fusion protein PLZFRAR $\alpha$ and the efficacy of arsenic despite only moderate differentiation ability challenged this idea. PML/RAR $\alpha$ degradation must also trigger the clearance of the most immature cancer initiating cells in order to be curative (Nasr et al. 2008; Rice and de Thé 2014). This example shows that inducing differentiation is not sufficient if not associated with a blockage of CSCs self-renewal.

Second, the efficacy of actual CSC- and niche-targeting drugs can (and should) be interpreted probabilistically. CSC-targeting drugs cannot guarantee a definitive cure if stemness is a relational-extrinsic or a systemic property, as non-CSCs might acquire stemness and lead to resistance or relapse. However, they could still happen to cure the patient if no cancer cell acquires stemness. Thus, the probability that a CSC-targeting drug will cure cancer is correlated to the probability of stemness acquisition (Figure 3, left). The same goes for niche-targeting drugs. They cannot guarantee a definitive cure if stemness is a systemic property, as other factors might induce stemness. However, they might still happen to be curative. In a given cancer, the niche could be the most frequent factor of stemness acquisition without being the only possible one. In such cases, stemness would be classified as a systemic property, and the efficiency of niche-targeting drugs would correlate with the probability of stemness acquisition by other factors (Figure 3, right).
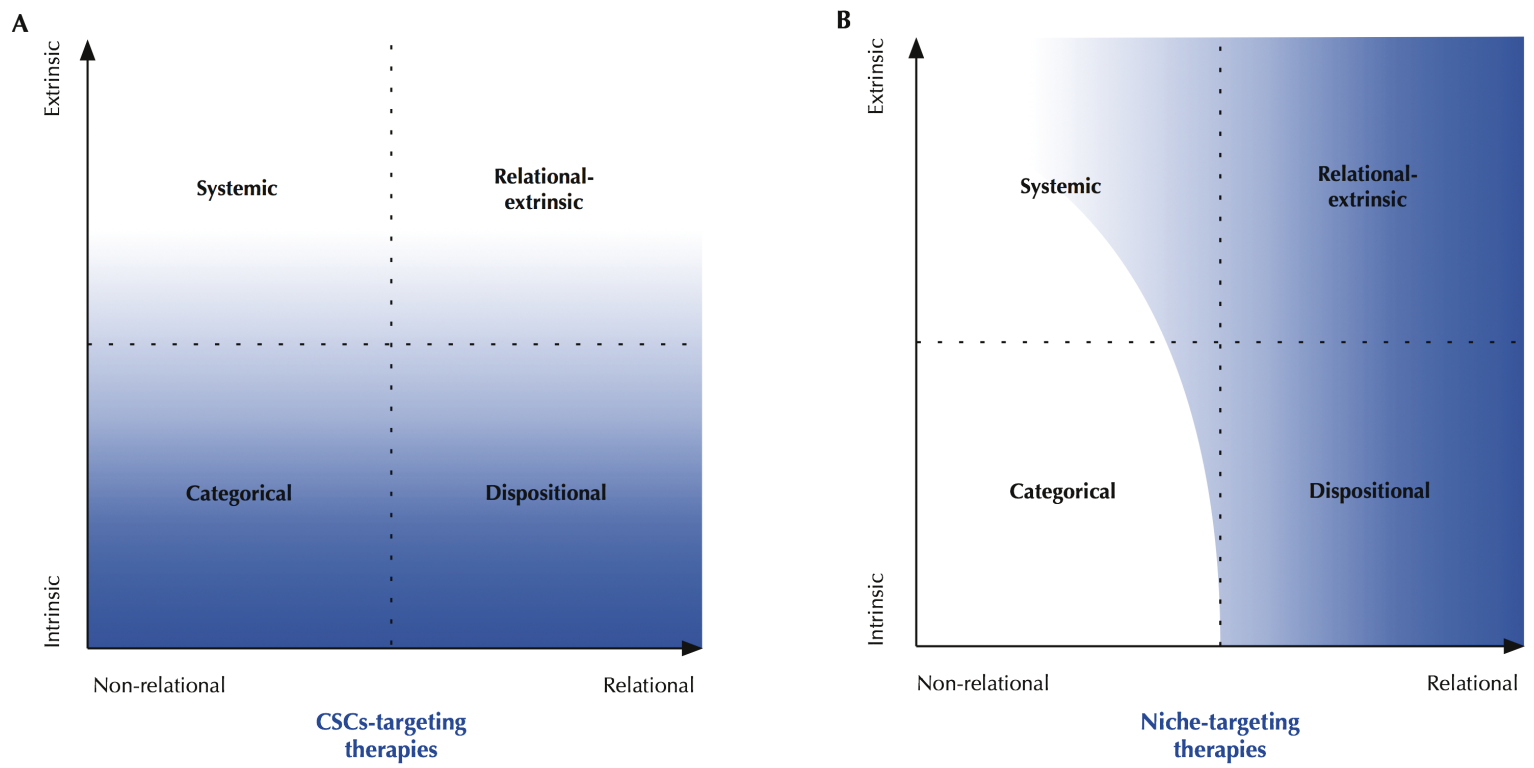

Figure 3 - Probabilistic interpretation of the efficiency of targeting drugs depending on stemness identity. Gray indicates the efficacy of the therapy, and white represents failure.

Third, the question of whether cancer progression might cause changes in stemness identity through particular mutations should be addressed. Constitutive activation of signaling pathways following some cancer mutations can make the cell independent from extrinsic signaling (Feitelson et al. 2015; Hanahan and Weinberg 2011). If such mutations could make CSCs independent from their niche, it could transform stemness disposition into a categorical property. In addition, some new mutations might lead to the reacquisition of self-renewal ability. For example, MOZ-TIF2, an acute myeloid leukemia (AML)-associated fusion gene, can transform myeloid progenitors into CSCs by inducing the ability to long-term self-renew (Huntly et al. 2004). Another AMLassociated fusion protein called MLL-ENL can also contribute to the transformation of committed progenitors that normally lack self-renewal capacity (Cozzio et al. 2003). Acquisition of such mutations can lead to the transformation of chronic leukemia into acute phases (Jamieson, Weissman, and Passegué 2004). These particular events can challenge the therapeutic consequences of stemness identity. On the one hand, stemness acquisition through mutations makes it an intrinsic property of the mutated cells. A CSC-targeting strategy should therefore be effective. On the other hand, these mutations result in the production of new populations of CSCs, as if it was an extrinsic property acquired by cancer non-stem cells, and therefore could lead to relapse after elimination of the initial pool of CSCs. 


\section{Conclusion}

Cloning and iPSC technologies have revealed that differentiated cells can dedifferentiate to a stem cell state. Not only can we induce stemness by manipulating the cells in vitro, but the process might also happen naturally in vivo, at least in some particular circumstances such as regeneration, or cancers. Such phenomena raise biological and philosophical questions about the identity of stem cells. Biologically stated, the questions are twofold: can cells acquire stemness, and does the niche play a major role in stemness activity?

A philosophical analysis shows that depending on the answer one gives to these two questions, stemness can be either a categorical property, a dispositional property, a relational-extrinsic property, or a systemic property. These four possibilities are not mutually exclusive. For example, current data suggest that stemness is a dispositional property in hematopoietic stem cells and a systemic property in epithelial cancer stem cells. In the hematopoietic system, the niches play an important role in controlling stem cells' self-renewal and differentiation, seemingly without being able to induce stemness in non-stem cells. In contrast, several data report plasticity in epithelial tissues and support the idea that non-stem cells could acquire stemness without necessarily involving a particular niche, especially in cancers. In addition to clarifying the possible identities of stem cells, such classification allows one to compare the potential efficacy of different therapeutic strategies against cancers. CSC-targeting will be much more efficient if stemness is a categorical or dispositional property than if it is a relational-extrinsic or a systemic property. Niche-targeting will be more efficient if stemness is a dispositional or relational-extrinsic property. Lastly, the ability of differentiation therapy to cure cancer will be correlated to the stability of the induced differentiation.

\section{References}

Alison, Malcolm R., Susan M. Lim, and Linda J. Nicholson. 2011. “Cancer Stem Cells: Problems for Therapy?” J Pathol 223 (2): 147-61.

Arai, Fumio, and Toshio Suda. 2008. "Quiescent Stem Cells in the Niche." In StemBook, ed. The Stem Cell Research Community. Cambridge: Harvard Stem Cell Institute. doi/10.3824/stembook.1.6.1.

Arthur, Wallace. 1997. The Origin of Animal Body Plans. Cambridge: Cambridge University Press.

Barroca, Vilma, et al. 2009. "Mouse Differentiating Spermatogonia Can Generate Germinal Stem Cells In Vivo." Nat Cell Biol 11 (2): 190-96.

Bernardos, Rebecca L., et al. 2007. "Late-Stage Neuronal Progenitors in the Retina Are Radial Muller Glia That Function as Retinal Stem Cells." J Neurosci 27 (26): 7028-40.

Blau, Helen M. 2014. "Sir John Gurdon: Father of Nuclear Reprogramming." Differentiation 88 (1): 10-12.

Bonnet, Dominique, and John E. Dick. 1997. "Human Acute Myeloid Leukemia Is Organized as a Hierarchy That Originates from a Primitive Hematopoietic Cell." Nat Med 3 (7): 730-37.

Brawley, Crista, and Erika Matunis. 2004. "Regeneration of Male Germline Stem Cells by Spermatogonial Dedifferentiation In Vivo." Science 304 (5675): 1331-34.

Briggs, Robert, and Thomas J. King. 1952. "Transplantation of Living Nuclei from Blastula Cells into Enucleated Frogs' Eggs." Proc Natl Acad Sci USA 38 (5): 455-63.

Brown, M. E., et al. 2010. "Derivation of Induced Pluripotent Stem Cells from Human Peripheral Blood T Lymphocytes." PLoS One 5 (6): e11373.

Bryder, David, Derrick J. Rossi, and Irving L. Weissman. 2006. "Hematopoietic Stem Cells: The Paradigmatic Tissue-Specific Stem Cell." Am J Pathol 169 (2): 338-46.

Burns, David, and Helen M. Blau. 2014. "Perspective for Special Gurdon Issue for Differentiation: Can Cell Fusion Inform Nuclear Reprogramming?" Differentiation 88 (1): 27-28.

Chaffer, Christine L., et al. 2011. "Normal and Neoplastic Nonstem Cells Can Spontaneously Convert to a StemLike State." Proc Natl Acad Sci USA 108 (19): 7950-55.

Chaffer, Christine L., et al. 2013. "Poised Chromatin at the ZEB1 Promoter Enables Breast Cancer Cell Plasticity and Enhances Tumorigenicity." Cell 154 (1): 61-74.

Cheng, J., et al. 2008. "Centrosome Misorientation Reduces Stem Cell Division During Ageing." Nature 456 (7222): 599-604.

Choi, Su Mi, et al. 2011. "Reprogramming of EBV-Immortalized B-Lymphocyte Cell Lines into Induced Pluripotent Stem Cells." Blood 118 (7): 1801-5. 
Christen, Bea, et al. 2010. "Regeneration and Reprogramming Compared." BMC Biol 8: 5.

Clevers, Hans, Kyle M. Loh, and Roel Nusse. 2014. "An Integral Program for Tissue Renewal and Regeneration: Wnt Signaling and Stem Cell Control." Science 346 (6205). doi:10.1126/science.1248012.

Cox, Jesse L., and Angie Rizzino. 2010. "Induced Pluripotent Stem Cells: What Lies Beyond the Paradigm Shift." Exp Biol Med (Maywood) 235 (2): 148-58.

Cozzio, Antonio, et al. 2003. "Similar MLL-Associated Leukemias Arising from Self-Renewing Stem Cells and Short-Lived Myeloid Progenitors." Genes Dev 17 (24): 3029-35.

Davis, R. L., H. Weintraub, and Andrew B. Lassar. 1987. "Expression of a Single Transfected cDNA Converts Fibroblasts to Myoblasts." Cell 51 (6): 987-1000.

Donati, Giacomo, and Fiona M. Watt. 2015. "Stem Cell Heterogeneity and Plasticity in Epithelia." Cell Stem Cell 16 (5): 465-76.

Echeverri, Karen, Jon D. Clarke, and Elly M. Tanaka. 2001. "In Vivo Imaging Indicates Muscle Fiber Dedifferentiation Is a Major Contributor to the Regenerating Tail Blastema." Dev Biol 236 (1): 151-64.

Eminli, Sarah, et al. 2009. "Differentiation Stage Determines Potential of Hematopoietic Cells for Reprogramming into Induced Pluripotent Stem Cells." Nat Genet 41 (9): 968-76.

Feitelson, Mark A., et al. 2015. "Sustained Proliferation in Cancer: Mechanisms and Novel Therapeutic Targets." Semin Cancer Biol. doi: 10.1016/j.semcancer.2015.02.006.

Gracio, Filipe, Joaquim Cabral, and Bruce Tidor. 2013. "Modeling Stem Cell Induction Processes." PLoS One 8 (5): e60240.

Grafi, Gideon. 2004. "How Cells Dedifferentiate: A Lesson from Plants." Dev Biol 268 (1): 1-6.

Greaves, Mel. 2013. "Cancer Stem Cells as 'Units of Selection.'” Evol Appl 6 (1): 102-8.

Gupta, Piyush B., et al. 2011. "Stochastic State Transitions Give Rise to Phenotypic Equilibrium in Populations of Cancer Cells." Cell 146 (4): 633-44.

Gurdon, John B. 1962. "The Developmental Capacity of Nuclei Taken from Intestinal Epithelium Cells of Feeding Tadpoles." J Embryol Exp Morphol 10: 622-40.

Hanahan, Douglas, and Robert A. Weinberg. 2011. "Hallmarks of Cancer: The Next Generation." Cell 144 (5): 646-74.

Hanna, Jacob, et al. 2008. "Direct Reprogramming of Terminally Differentiated Mature B Lymphocytes to Pluripotency." Cell 133 (2): 250-64.

Hochedlinger, Konrad, and Rudolf Jaenisch. 2002. "Monoclonal Mice Generated by Nuclear Transfer from Mature B and T Donor Cells." Nature 415 (6875): 1035-38.

Hochedlinger, Konrad, and Rudolf Jaenisch. 2006. "Nuclear Reprogramming and Pluripotency." Nature 441 (7097): 1061-7.

Huang, Sui. 2011. "Systems Biology of Stem Cells: Three Useful Perspectives to Help Overcome the Paradigm of Linear Pathways." Philos Trans R Soc Lond B Biol Sci 366 (1575): 2247-59.

Huntly, Brian J. P., et al. 2004. "MOZ-TIF2, but Not BCR-ABL, Confers Properties of Leukemic Stem Cells to Committed Murine Hematopoietic Progenitors." Cancer Cell 6 (6): 587-96.

Jamieson, Catriona H. M., Irving L. Weissman, and Emmanuelle Passegué. 2004. "Chronic versus Acute Myelogenous Leukemia: A Question of Self-Renewal." Cancer Cell 6 (6): 531-33.

Johnson, Mark H. 2001. "Functional Brain Development During Infancy." In Blackwell Handbook of Infant Development, ed. Gavin Bremner and Alan Fogel, 169-90. Oxford: Blackwell Publishers.

Jopling, Chris, et al. 2010. "Zebrafish Heart Regeneration Occurs by Cardiomyocyte Dedifferentiation and Proliferation." Nature 464 (7288): 606-9.

Kai, T., and A. Spradling. 2004. "Differentiating Germ Cells Can Revert into Functional Stem Cells in Drosophila melanogaster Ovaries." Nature 428 (6982): 564-69.

Kikuchi, Kazu, et al. 2010. "Primary Contribution to Zebrafish Heart Regeneration by Gata4(+) Cardiomyocytes." Nature 464 (7288): 601-5.

King, Thomas J., and Robert Briggs. 1955. "Changes in the Nuclei of Differentiating Gastrula Cells, as Demonstrated by Nuclear Transplantation." Proc Natl Acad Sci USA 41 (5): 321-25.

Kreso, Antonija, and John E. Dick. 2014. "Evolution of the Cancer Stem Cell Model." Cell Stem Cell 14 (3): 27591.

Kuroda, Yamasuma, et al. 2010. "Unique Multipotent Cells in Adult Human Mesenchymal Cell Populations." Proc Natl Acad Sci 107 (19): 8639-43.

Landsberg, Jennifer, et al. 2012. "Melanomas Resist T-Cell Therapy Through Inflammation-Induced Reversible Dedifferentiation." Nature 490 (7420): 412-16.

Laplane, Lucie. 2015. "Stem Cell Epistemological Issues." In Stem Cell Biology and Regenerative Medicine, ed. Pierre Charbord and Charles Durand, 693-712. Aalborg: River Publisher. 
Laplane, Lucie. n.d. Cancer Stem Cells. Cambridge: Harvard University Press, forthcoming.

Lohmann, Jan U. 2008. "Plant Stem Cells: Divide et Impera." In Stem Cells: From Hydra to Man, ed. Thomas C. G. Bosch. Dordrecht: Springer.

Maienschein, Jane. 2014. Embryos Under the Microscope: The Diverging Meanings Of Life. Cambridge: Harvard University Press.

Mani, Sendurai A., et al. 2008. "The Epithelial-Mesenchymal Transition Generates Cells with Properties of Stem Cells." Cell 133 (4): 704-15.

Nasr, Rihab, et al. 2008. "Eradication of Acute Promyelocytic Leukemia-Initiating Cells Through PML-RARA Degradation." Nat Med 14 (12): 1333-42.

Nobel Foundation. 2012. "The Nobel Prize in Physiology or Medicine 2012." Nobelprize.org. Nobel Media A B 2014. http://www.nobelprize.org/nobel_prizes/medicine/laureates/2012/.

Nye, Holly L., et al. 2003. "Regeneration of the Urodele Limb: A Review." Dev Dyn 226(2): 280-94.

Pradeu, Thomas, et al. n.d. "Defining "Development." Curr Top Dev Biol, in press.

Ramachandran, Rajeth, Blake V. Fausett, and Daniel Goldman. 2010. “Ascl1a Regulates Muller Glia Dedifferentiation and Retinal Regeneration Through a Lin-28-Dependent, Let-7 microRNA Signalling Pathway." Nat Cell Biol 12 (11): 1101-7.

Rather, L. J. 1978. The Genesis of Cancer: A Study in the History of Ideas. Baltimore: Johns Hopkins University Press.

Reya, Tannishtha, et al. 2001. "Stem Cells, Cancer, and Cancer Stem Cells." Nature 414 (6859): 105-11.

Rice, Kim L., and Huges de Thé. 2014. "The Acute Promyelocytic Leukaemia Success Story: Curing Leukaemia Through Targeted Therapies." J Intern Med 276 (1): 61-70.

Satoh, Akira, Susan V. Bryant, and David M. Gardiner. 2008. "Regulation of Dermal Fibroblast Dedifferentiation and Redifferentiation During Wound Healing and Limb Regeneration in the Axolotl." Dev Growth Differ 50 (9): 743-54.

Satoh, Akira, et al. 2008. "Neurotrophic Regulation of Epidermal Dedifferentiation During Wound Healing and Limb Regeneration in the Axolotl (Ambystoma mexicanum)." Dev Biol 319 (2): 321-35.

Scheel, Christine, et al. 2011. "Paracrine and Autocrine Signals Induce and Maintain Mesenchymal And Stem Cell States in the Breast." Cell 145 (6): 926-40.

Schofield, Raymond. 1978. "The Relationship Between the Spleen Colony-Forming Cell and the Haemopoietic Stem Cell." Blood Cells 4 (1-2): 7-25.

Schofield, Raymond. 1983. "The Stem Cell System." Biomed Pharmacother 37 (8): 375-80.

Sheng, X. Rebecca, Crista M. Brawley, and Erika L. Matunis. 2009. "Dedifferentiating Spermatogonia Outcompete Somatic Stem Cells for Niche Occupancy in the Drosophila testis." Cell Stem Cell 5 (2): 191203.

Spemann, Hans. 1938. Embryonic Development and Induction. New Haven: Yale University Press.

Stadtfeld, Matthias, and Konrad Hochedlinger. 2010. "Induced Pluripotency: History, Mechanisms, and Applications." Genes Dev 24 (20): 2239-63.

Staerk, Judith, et al. 2010. "Reprogramming of Human Peripheral Blood Cells to Induced Pluripotent Stem Cells." Cell Stem Cell 7 (1): 20-24.

Tada, Masako, et al. 2001. "Nuclear Reprogramming of Somatic Cells by In Vitro Hybridization with ES Cells." Curr Biol 11 (19): 1553-58.

Takahashi, Kazutoshi, and Shinya Yamanaka. 2006. "Induction of Pluripotent Stem Cells from Mouse Embryonic and Adult Fibroblast Cultures by Defined Factors." Cell 126 (4): 663-76.

Takahashi, Kazutoshi, et al. 2007. "Induction of Pluripotent Stem Cells from Adult Human Fibroblasts by Defined Factors." Cell 131 (5): 861-72.

Tetteh, Paul W., Henner F. Farin, and Hans Clevers. 2015. "Plasticity Within Stem Cell Hierarchies in Mammalian Epithelia." Trends Cell Biol 25 (2): 100-108.

Thirant, Cécile, et al. 2011. "Clinical relevance of Tumor Cells with Stem-Like Properties in Pediatric Brain Tumors." PLoS One 6 (1): e16375.

Till, James E., and Ernest A. McCulloch. 1980. "Hemopoietic Stem Cell Differentiation." Biochim Biophys Acta 605 (4): 431-59.

Vermeulen, Louis, et al. 2012. “The Developing Cancer Stem-Cell Model: Clinical Challenges and Opportunities.” Lancet Oncol 13 (2): e83-89.

Vogel, Gretchen, and Dennis Normile. 2012. "Nobel Prize in Physiology or Medicine: Reprogrammed Cells Earn Biologists Top Honor." Science 338 (6104): 178-79. 
Wakao, Shohei, Masaaki Kitada, and Mari Dezawa. 2013. "The Elite and Stochastic Model for iPS Cell Generation: Multilineage-Differentiating Stress Enduring (Muse) Cells Are Readily Reprogrammable into iPS Cells." Cytometry Part A 83A (1): 18-26.

Wan, Jin, Rajesh Ramachandran, and Daniel Goldman. 2012. "HB-EGF Is Necessary and Sufficient for Muller Glia Dedifferentiation and Retina Regeneration." Dev Cell 22 (2): 334-47.

Wang, Z. Y., and Z. Chen. 2008. "Acute Promyelocytic Leukemia: From Highly Fatal to Highly Curable." Blood 111 (5): 2505-15.

Weatherson, Brian, and Dan Marshall. 2014. "Intrinsic vs. Extrinsic Properties." In The Stanford Encyclopedia of Philosophy, ed. Edward N. Zalta. http://plato.stanford.edu/archives/fall2014/entries/intrinsic-extrinsic/.

Weissman, Irving L. 2000. "Stem Cells: Units of Development, Units of Regeneration, and Units in Evolution." Cell 100 (1): 157-68.

Wilmut, Ian, et al. 1997. "Viable Offspring Derived from Fetal and Adult Mammalian Cells." Nature 385 (6619): 810-13.

Yamanaka, Shinya 2009. "Elite and Stochastic Models for Induced Pluripotent Stem Cell Generation." Nature 460 (7251): 49-52.

Yamanaka, Shinya. 2013. "The Winding Road To Pluripotency (Nobel Lecture)." Angew Chem Int Ed Eng/ 52 (52): 13900-909.

Zhu, Wei, et al. 2012. "Activation of Germline-Specific Genes Is Required for Limb Regeneration in the Mexican Axolotl." Dev Biol 370 (1): 42-51. 